\title{
Classical Hodgkin lymphoma arising from heterotopic Warthin's tumor in the cervical lymph node: A case report
}

\author{
LI JUN $^{1}$ and $\mathrm{ZHU} \mathrm{MING}{ }^{2}$ \\ ${ }^{1}$ Department of Pathology, The First Affiliated Hospital, College of Medicine, Zhejiang University, Hangzhou, \\ Zhejiang 310003; ${ }^{2}$ Department of Head and Neck, Zhejiang Tumor Hospital, Hangzhou, Zhejiang 310021, P.R. China
}

Received November 5, 2017; Accepted April 17, 2018

DOI: $10.3892 / \mathrm{ol} .2018 .8682$

\begin{abstract}
Heterotopic Warthin's tumor (WT) arising from the cervical lymph nodes is uncommon and WT presenting concomitantly with classical Hodgkin's lymphoma has only been previously reported three times in English literature. The current study presents an unusual case of classical Hodgkin lymphoma (CHL) involving the heterotopic WT in a 59-year-old male. Histopathologic examination revealied a WT with extensive expansion of mixed-cellularity CHL in a lymph node in the right of the neck. Clinical staging was determined as stage IA disease. The patient received four courses of chemotherapy and local consolidative radiotherapy, no evidence of disseminated lymphoma was observed over the 6-month follow-up. To the best of our knowledge, this is the first well documented collision tumor between CHL and heterotopic WT of the cervical lymph nodes. The present case also expands the anatomical site of malignant lymphomas associated with WT.
\end{abstract}

\section{Introduction}

Warthin's tumor (WT), composed of cystic or glandular spaces lined by oncocytic epithelium and lymphoid reactive stroma, is the second most common benign salivary gland neoplasm. It is exclusively found in or near the parotid gland, and rarely been described in the minor salivary gland or other sites such as the cervical lymph nodes (1). Malignant lymphoma involving WT is uncommon and is almost single-case reports with 28 cases, mostly are non-Hodgkin B-cell lymphomas with a prevalence of follicular lymphomas (2-8). The co-existence of WT and classical Hodgkin lymphoma (CHL) is extremely rare with only 3 reported cases, which all occurred in the parotid gland $(3,4,7)$. Herin we describe a case of mixed-cellularity

Correspondence to: Dr Li Jun, Department of Pathology, The First Affiliated Hospital, College of Medicine, Zhejiang University, 79 Qingchun Road, Hangzhou, Zhejiang 310003, P.R. China E-mail: lijunfee@163.com

Key words: Warthin's tumor, classical, Hodgkin lymphoma, heterotopic, collision tumor
CHL (MCCHL) that primarily presented as part of the ectopic WT in a lymph node of the neck. To our knowledge this is the first report describing a concomitant occurrence of MCCHL within a heterotopic WT of the cervical lymph nodes.

\section{Case report}

A 59-year-old male presented with a 1-month history of two unapparent masses in his right neck. No pain, fever, night sweats or weight loss was found. His medical history included a 40-year history of heavy smoking and 8-year history of hypertension. On physical examination, two solitary, mobile, and non-tender masses with a smooth surface was palpated in the right neck.

All laboratory tests including a complete blood count and tumor markers were within normal limits. Ultrasound sonography examination of the head and neck revealed two swollen lymph nodes below the sternocleidomastoid muscle of the right neck, were $1.5 \times 0.5,1.3 \times 1.2 \mathrm{~cm}$ in size, respectively. It is no clear boundary between the cortex and medulla of the lymph nodes (Fig. 1). No other abnormalities were found in the parotid gland, submaxillary gland, sublingual gland, or left cavity. One of lymph nodes was completely resected, which was easily extirpated. The tissue was subjected to a series of pathological examinations.

Grossly, the excised specimen was well-demarcated, measured $1.3 \times 1.2 \times 1.2 \mathrm{~cm}$. It appeared as a multi-fissured mass in part of cross section, and grayish tissue could be seen around the fissured spaces. Histological examination showed the presence of a WT, composed of glandular or cystic structures, a papillary cystic arrangement in some areas, lined with characteristic bilayered epithelium, comprising columnar eosinophilic or oncocytic cells surrounded by smaller basal cells (Fig. 2A-D). The cystic spaces contained eosinophilic material with occasional crystal formation. The lymphoid component comprised diffusely infiltrating abnormal lymphoid tissue, consisting of a large number of small lymphocytes with admixture of occasional eosinophils, plasma cells and histiocytes. Classic binucleated Reed-Sternberg (RS) cells and other types of RS cells with large, pleomorphic nucleus and prominent eosinophilic nucleoli were easily observed in the mixed background (Fig. 2B-D). Immunohistochemically, the RS cells were strongly positive for CD30 (Fig. 3A) and CD15 (Fig. 3B) and LMP1, and a weak positivity for PAX5 
(Fig. 3C), but negative for CKpan, CD45, CD3, CD20, CD10, BCL6, MUM-1, CD21, CD23, CD68, ALK, or PD-1. The Ki-67 proliferative index was more than $60 \%$ and EBER in situ hybridization was also positive in RS cells (Fig. 3D). A diagnosis of MCCHL with coexistent heterotopic WT of the cavical lymph node was made based on the findings described above.

A thorough staging examination including contrast enhanced computed tomography of the chest, abdomen and pelvis, and bone marrow biopsy revealed no evidence of dissemination of CHL. Staging workup demonstrated Ann Arbor stage IA. The patient received four courses of chemotherapy (ABVD: Adriamycin, bleomycin, vincristine, and dacarbazine) followed by local consolidative radiotherapy (20 Gy). At the time of this report, the patient has been followed up for 6 months, without evidence of disease or lymphomas disseminated.

\section{Discussion}

WT is the second most common benign salivary gland neoplasm, composed of glandular and often cystic structures lined by characteristic bilayered oncocytic epithelium and abundant lymphoid stroma. It usually presents in the fifth to seventh decades of life and has a slight male predominance with a male-to-female ratio of 4.6:1, that mostly affects to the heavy smokers. WT typically occurrs intraparotid or periparotid gland and occasionally been seen in the small salivary gland (9).

Heterotopic salivary gland tissue may occur in the lymph node, external auditory canal, middle ear, mandible, tongue, thyroid, and in the upper and lower neckregions (1). The neoplasms may arise from heterotopic salivary tissue in uncommon cases, and 60-80\% were benign. WT is the frequent lesion, following by pleomorphic adenoma. The lesions arising from heterotopic salivary tissue may present as a mass, cyst or draining sinus.

The histogenesis of WT and heterotopic WT remains unclear. A predominant theory is that WT develops from heterotopic salivary ductal inclusions in intra/peri parotid, cervical lymph nodes or other ectopic site (10). It may stimulates and acts by smoking, The histogenesis may underlie the heterotopic WT and the tumorigenesis of malignant lymphoma developing in WT. The present case was primary heterotopic WT in the cervical lymph node based on the typical histologic changes and no tumor found in three major salivary glands or minor salivary glands.

Malignant transformation in WT is unusual, and may involve either the epithelial or lymphoid component. Lymphomas associated with WT are very rare with 29 reported cases including our case in the English literature. With available information, there was a male predominance (males, $\mathrm{n}=25,86 \%$ ) with a mean age of 65 years (range, 49-102). The vast majority of cases $(n=20,80 \%)$ affected the parotid gland. Pathologically, the more types were follicular lymphoma (12/29, 41\%), DLBCL (5/29, 17\%) and CHL (4/29, 14\%). Small lymphocytic leukemia/lymphoma ( 2 case, $7 \%$ ), extranodal mucosa-associated lymphoid tissue (MALT)-type (1 case, 3\%), mantle cell lymphoma (1 case, $3 \%$ ), nodular lymphocyte-predominant Hodgkin lymphoma

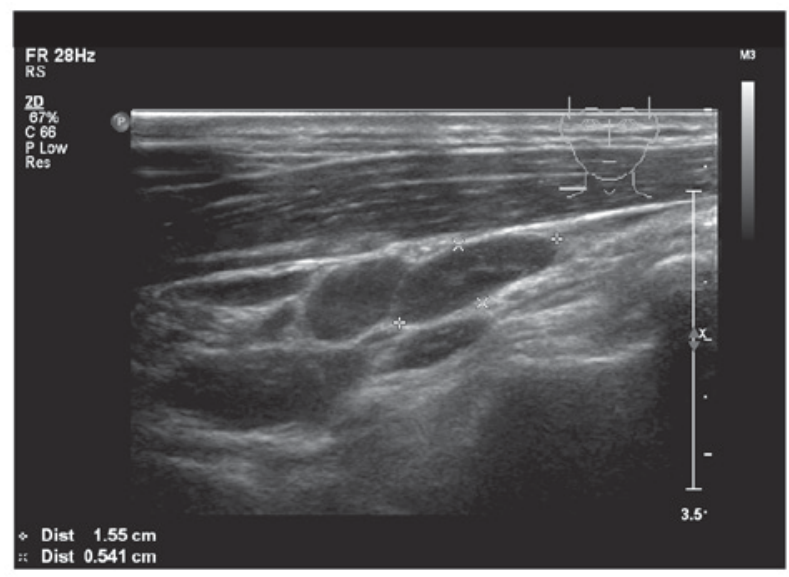

Figure 1. Ultrasound sonography examination revealed two lymph nodes, $1.5 \times 0.5$ and $1.3 \times 1.2 \mathrm{~cm}$ in size with no clear boundary between the cortex and medulla below the sternocleidomastoid muscle of the right neck.
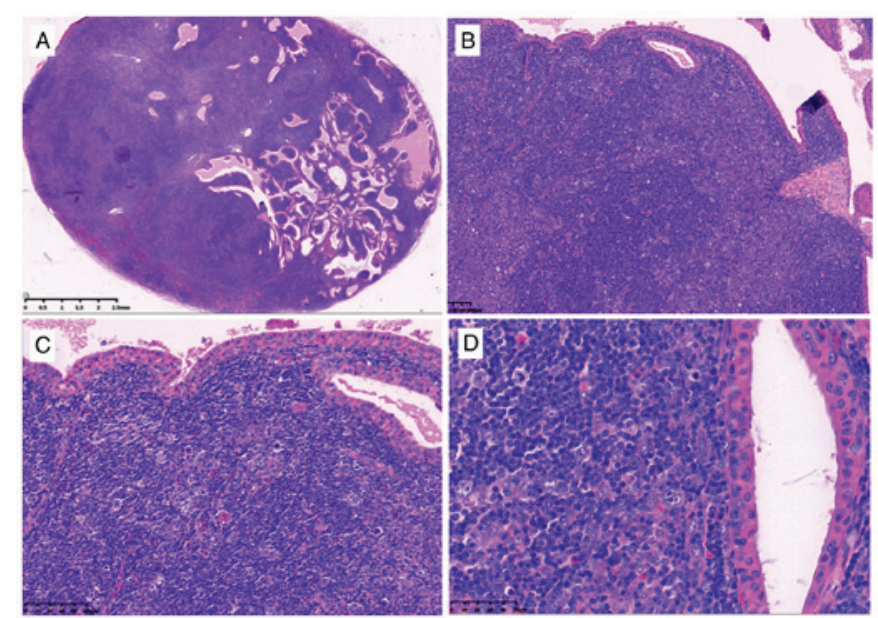

Figure 2. Histological examination revealed the presence of a Warthin's tumor, composed of inner columnar eosinophilic cells surrounded by smaller basal cells (A-D); Classic RS cells and other types of RS cells are easily observed in the mixed background (B-D). Magnification (A) x5, (B) x100, (C) x200 and (D) x400. RS, Reed-Sternberg.
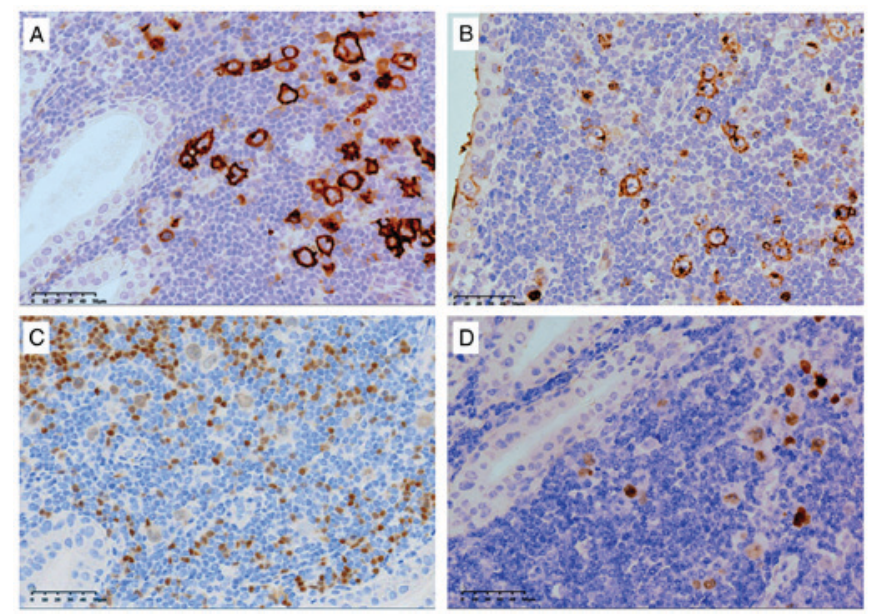

Figure 3. Immunohistochemical analysis revealed the RS cells were strongly positive for (A) CD30 and (B) CD15 and weakly positive for (C) PAX5. (D) Epstein-Barr virus encoded RNA in situ hybridization was also positive in RS cells. Magnification, x400. CD, cluster of differentiation; PAX5, paired box protein Pax-5; RS, Reed-Sternberg. 
Table I. Summary of lymphomas involving heterotopic WT and CHL first diagnosed in WT.

\begin{tabular}{|c|c|c|c|c|c|c|c|c|}
\hline $\begin{array}{l}\text { Author } \\
\text { (year) }\end{array}$ & Age & Sex & Subtype & Location & Involved organs & Stage $^{a}$ & $\begin{array}{l}\text { Follow-up } \\
\text { (months) }\end{array}$ & (Refs.) \\
\hline Miller et al & 49 & $\mathrm{M}$ & $\begin{array}{l}\text { NHL (small cleaved } \\
\text { follicular center) }\end{array}$ & Angle of mandible & No & IA & AWD, $5 \mathrm{~m}$ & (2) \\
\hline Park et al & 68 & $\mathrm{~F}$ & NHL (follicular center) & Periparorid LN & No & IA & NED, $63 \mathrm{~m}$ & (5) \\
\hline Gorai et al & 102 & $\mathrm{M}$ & NHL (DLBCL) & Neck LN & & NA & $\begin{array}{l}\text { Died of body } \\
\text { debility, } 10 \mathrm{~m}\end{array}$ & (6) \\
\hline Melato et al & 69 & $\mathrm{M}$ & CHL (mixed cellularity) & Right parotid & $\begin{array}{l}\text { Inguinal and } \\
\text { cervical LN }\end{array}$ & NA & DOD, $13 \mathrm{~m}$ & (3) \\
\hline Badve et al & 76 & $\mathrm{M}$ & CHL (no distinguish) & Left interparotid & Left mediastinum & NA & NED, $24 \mathrm{~m}$ & (4) \\
\hline Liu et al & 78 & $\mathrm{M}$ & CHL (lymphocyte-rich) & Right parotid & $\begin{array}{l}\text { Hilar, mediastinal, } \\
\text { Abdominal LN }\end{array}$ & IVB & $\mathrm{DOD}, 7 \mathrm{~m}$ & (7) \\
\hline Present study & 59 & M & CHL (mixed cellularity) & Right cervical LN & No & IA & NED, $6 \mathrm{~m}$ & \\
\hline
\end{tabular}

${ }^{a}$ Ann Arbor stage (11). M, male; LN, lymph nodes; NED, no evidence of disease; DOD, died of disease; AWD, alive with disease; NA, not available; WT, Warthin's tumor; NHL, Non-Hodgkin's lymphoma; DLBCL, Diffuse large B cell lymphoma; CHL, classic Hodgkin's lymphoma.

(NLPHL, 1 case, 3\%), T-cell lymphoma (TCL, peripheral T-cell lymphoma, 1 case; T-lymphoblastic lymphoma, 1 case, 7\%), and not classified lymphoma (1 case, $3 \%$ ) were also recorded. On survival analysis, the lymphoma type (DLBCL and TCL had poor prognosis, $\mathrm{P}=0.001)$ and tumor stage (I/II vs. III/IV, $\mathrm{P}=0.048)(11)$ carried prognostic significance. Further analysis showed that 4 cases of concomitan heterotopic WT involving lymphoma had been reported $(2,5,6) .3$ of 4 cases were NHL and 1 case (ours) was CHL. The majority of them were male (3/4 cases) and the anatomical site of all cases was the lower neckregions (Table I).

The primary salivary Hodgkin lymphoma (HL) including CHL and NLPHL is also rare, mostly occurred in the parotid, representing only 3.5 to $6 \%$ of primary parotid gland lymphomas and $0.3 \%$ of all HL cases in general $(12,13)$. Agaimy et al (14) reported 9 cases of intraparotid HL, are the largest group that have been reported. As mentioned above, there were only 3 cases reported of CHL involving WT, which all occured in the parotid gland (Table I) $(3,4,7)$. The present case arised from heterotopic WT in the neck, that is the first one reported. All reported cases including our case were older male (59-78 years). Pathologically, 2 cases contained a mixed-cellularity subtype, and 1 was lymphocyte-rich subtype. The other case was not further distinguished with regard to the lymphoma subtype. Patients were followed up for 6 to 24 months, and 2 were died of disease, 2 were no evidence of disease.

The development of malignant lymphoma in WT and heterotopic WT is incompletely understood. Intra-/peri-glandular lymph nodes or WT lymphoid stroma might be either the site of origin of the lymphoma or the site of secondary involvement by disseminated disease $(7,15)$. The possibility for the lymphoma to originate in the lymphoid tissue of WT is supported by several reports indicating that WT-associated lymphoma may remain a localized disease for long periods of time $(2,5)$. On the other hand, the major studies indicate that the lymphoid stroma in WT belongs to the systemic lymphoid tissue and can be involved in disseminated lymphoma $(3,4,7)$. In the advanced stages, the distinction between primary and secondary lymphomas may be impossible and unnecessary. Concerning the site of origin of CHL in WT evidences are inconclusive, in 3 of the 4 reported cases, the disease was simultaneously present in WT and in cervical lymph nodes, whereas, in the other case, it exclusively involved an intraparotid. Although few, the prognosis of those collision tumors seems to be related to the Ann Arbor stage of CHL.

In conclusion the present study reports the first case that is MCCHL arising from heterotopic WT of the cervical lymph node. It shows that neoplasms arising from heterotopic salivary tissue should be considered in the differential diagnosis for isolated neck masses, and the lymphoid stroma of heterotopic WT may be the site of CHL. Accurate diagnosis can be established after removal, and hence, it has to be carefully investigated, considering that the histological diagnosis of CHL may be very insidious especially in the context of WT with abundant lymphoid stroma. The present study also expands the anatomical site of malignant lymphomas associated with WT.

\section{Acknowledgements}

Not applicable.

\section{Funding}

The present study was funded by the 2017 Zhejiang Natural Fund (grant no. LY17H160009).

\section{Availability of data and materials}

The datasets used and/or analyzed during the current study are available from the corresponding author on reasonable request. 


\section{Authors' contributions}

$\mathrm{LJ}$ interpreted the patient data and was a major contributor in writing the manuscript. ZM undertook collection of images and reference literature. Each author read and approved the final manuscript.

\section{Ethics approval and consent to participate}

Not applicable.

\section{Consent for publication}

The patient provided written informed consent for the publication of case and clinical images.

\section{Competing interests}

The authors declare that they have no competing interests.

\section{References}

1. Ferlito A, Bertino G, Rinaldo A, Mannarà GM and Devaney KO A review of heterotopia and associated salivary gland neoplasms of the head and neck. J Laryngol Otol 113: 299-303, 1999.

2. Miller R, Yanagihara ET, Dubrow AA and Lukes RJ: Malignant lymphoma in the Warthin's tumor. Report of a case. Cancer 50: 2948-2950, 1982.

3. Melato M, Falconieri G, Fanin R and Baccarani M: Hodgink's disease occurring in a Warthin's tumor: First case report. Pathol Res Pract 181: 615-620, 1986.

4. Badve S, Evans G, Mady S, Coppen M and Sloane J: A case of Warthin's tumor with coexistent Hodgkin's disease. Histopathology 22: 280-281, 1993.
5. Park CK, Manning JT Jr, Battifora $\mathrm{H}$ and Medeiros LJ: Follicle center lymphoma and Warthin tumor involving the same anatomic site. Report of two cases and review of the literature. Am J Clin Pathol 113: 113-119, 2000.

6. Gorai S, Numata T, Kawada S, Nakano M, Tamaru J and Kobayashi T: Malignant lymphoma arising from heterotopic Warthin's tumor in the neck: Case report and review of the literature. Tohoku J Exp Med 212: 199-205, 2007.

7. Liu YQ, Tang QL, Wang LL, Liu QY, Fan S and Li HG: Concomitant lymphocyte-rich classical Hodgkin's lymphoma and Warthin's tumor. Oral Surg Oral Med Oral Pathol Oral Radiol 116: e117-e120, 2013.

8. Chu CY, Pan SC and Chang KC: EBV-positive diffuse large B-cell lymphoma of the elderly involving Warthin tumor. Pathol Int 65: 677-679, 2015.

9. Eveson JW and Simpson RHW: Warthin tumour. In: Barnes L, Eveson JW, Reichart P, Sidransky D (eds): WHO classification of tumours: Pathology and genetics of head and neck tumours. IARC Press, Lyon, p263-p265, 2005.

10. Kuzenko YV, Romanuk AM, Dyachenko OO and Hudymenko O: Pathogenesis of Warthin's tumors. Interv Med Appl Sci 8: 41-48, 2016.

11. Carbone PP, Kaplan HS, Musshoff K, Smithers DW and Tubiana M: Report of the committee on Hodgkin disease staging classification. Cancer Res 31: 1860-1861, 1971.

12. Feinstein AJ, Ciarleglio MM, Cong X, Otremba MD and Judson BL: Parotid gland lymphoma: Prognostic analysis of 2140 patients. Laryngoscope 123: 1199-1203, 2013.

13. Paliga A, Farmer J, Bence-Bruckler I and Lamba M: Salivary gland lymphoproliferative disorders: A Canadian tertiary center experience. Head Neck Pathol 7: 381-388, 2013.

14. Agaimy A, Wild V, Märkl B, Wachter DL, Hartmann A, Rosenwald A and Ihrler S: Intraparotid classical and nodular lymphocyte-predominant Hodgkin lymphoma: Pattern analysis with emphasis on associated lymphadenoma-like proliferations. Am J Surg Pathol 39: 1206-1212, 2015.

15. Giaslakiotis K, Androulaki A, Panagoulias G, Kyrtsonis MC, Lazaris AC, Kanakis DN and Patsouris ES: T cell lymphoblastic lymphoma in parotidectomy for Warthin's tumor: Case report and review of the literature. Int J Hematol 89: 359-364, 2009. 